\title{
Clinical Characteristics and Outcomes of Children Admitted to a Pediatric Intensive Care Unit Following a Severe Inflicted Injury: A Single-Center, Retrospective Study of Clinical Factors Associated with the Maltreatment of Children
}

\begin{abstract}
Jia-Huei Yan ${ }^{2}$, Ching-Yun Sun ${ }^{1}$, Ying- Hsien Huang ${ }^{1,2}$, Hsuan-Chang Kuo ${ }^{1}$, Ying-Jui Lin ${ }^{1}$, Chin-Ling Wu ${ }^{1}$ and Mei-
\end{abstract} $\mathrm{Hsin}_{\mathrm{Hsu}}{ }^{1}$

${ }^{1}$ Department of Pediatrics, Kaohsiung Chang Gung Memorial Hospital, Taiwan

${ }^{2}$ Department of Pediatrics, Chiayi Chang Gung Memorial Hospital, Taiwan

Submission: December 13, 2019; Published: January 08, 2020

*Corresponding author: Mei-Hsin Hsu, Department of Pediatrics, Kaohsiung Chang Gung Memorial Hospital, Taiwan

Abstract

Background: Child maltreatment is a widespread problem around the world, with an increasing amount of victims both at home and abroad. However, this issue often fails to be properly recognized, and promptly identifying maltreatment remains a challenge. In our study, we observe the clinical factors associated with child maltreatment at a tertiary care children's hospital.

Methods: We recruited 60 patients from January 2011 to May 2017 who were suspected victims of child abuse or neglect and were admitted to the Pediatric Intensive Care Unit. Patient characteristics, including age, gender, chronic comorbid conditions, immunization schedules, severity of disease, and length of PICU stay, and one-year outcome were recorded and analyzed.

Results: Of the 60 patients enrolled in this study, the median age when the suspected maltreatment event occurred was 9 months old. Our study revealed a higher incidence of underlying disease, new onset seizures, and missed vaccinations in the abused group. The length of hospital stay is 17.5 days and 5 days in the abused group and the neglected group, respectively $(\mathrm{P}<0.001)$. The abused group tend to have poor one-year outcome significantly

Conclusion: Abusive events not only result in harm to children but also because longer hospital stays that become financial burdens in health care. By better understanding the importance of early intervention against abuse, we can take action to save these children and prevent tragedies

Keywords: Child maltreatment; Child abuse and neglect; Severe inflicted injury

\section{Introduction}

Child maltreatment has long been a worldwide problem and can be life-threatening to children. Since the nineteen sixties, relevant authorities in the U.S. have been raising awareness on the issue. Prior to that, children had been viewed as their parents' property, and no law punished the abusive behavior. In 1946, John Caffey published a report of six infants with subdural hematoma and long bone fractures and indicated a relationship between them and child abuse [1]. In 1962, a landmark year, Henry Kempe and his colleagues published the article, "The battered- child syndrome, [2]" which sparked interest in researching child abuse and brought the subject to national attention [3]. The World Health Organization (WHO) defined child maltreatment, sometimes referred to as child abuse and neglect, as any form of physical and emotional ill-treatment, sexual abuse, neglect, and exploitation that results in actual or potential harm to the child's health, development, or dignity [4]. Abuse refers to caregivers that carry out acts of physical harm or sexual harassment toward children or acts that have adversely emotional effects on children's 
health and development. Meanwhile, neglect refers to caregivers' failure to provide an appropriate environment for children's development, such as health, education, emotional development, nutrition, shelter, and safe living conditions [4]. Based on data collected in the United States from the National Child Abuse and Neglect Data System (NCANDS) of the Children's Bureau, during the 2015 federal fiscal year (FFY), approximately 683,000 victims of child abuse and neglect were reported nationally, with a victim rate of 9.2 victims per 1,000 children [5]. In Taiwan, according to the Ministry of Health and Welfare, approximately 55,000 victims suspected of child maltreatment were reported in 2016, and only about 9,500 received intervention; most cases were reported by educational staff, followed by the police, social workers, and medical providers. The Centers of Disease and Control (CDC) in Taiwan traced immunization schedules, which revealed children who had been lost or neglected. Child maltreatment not only has the potential to cause death but can also have long-lasting negative effects on psychosocial and behavioral problems [6,7]. Despite widespread concern, child maltreatment is often underestimated. Preverbal children cannot report abusive events and recognizing occult injuries in a clinical setting poses a challenge for medical providers. A caregiver can pretend that child abuse is an accident by caregiver, while an accident can be the result of child neglect. Unreliable accounts from family members and unusual bruises or fractures raise suspicions of abuse. Furthermore, the definition of child maltreatment and parents' attitudes varies among different cultures and ethnic groups, which has affected the report rate and intervention by authorities [5,8]. More countries highlight the early detection of child maltreatment and aim to educate health care professionals regarding the screening of clinical symptoms and signs, identifying abuse, and making referrals to child protective services. Keeping abused children away from perpetrators is vital for preventing further harm on such children's physical and psychosocial health. In this study, we compared the characteristics of abused cases to analyze the clinical factors of child maltreatment.

\section{Material and Methods}

\section{Patients}

Table 1: Demographic data of 60 maltreatment children underwent neglected and abused events.

\begin{tabular}{|c|c|c|c|c|}
\hline & N (\%) & Neglected $(n=43)$ & Abused $(n=17)$ & p-value \\
\hline Gender (boy/girl) & $40 / 20$ & $27 / 16$ & $13 / 4$ & 0.311 \\
\hline Age at injury [months; median (IQR)] & $9(19)$ & $10(21.0)$ & $8(21.5)$ & 0.902 \\
\hline Chronic comorbid conditions [n (\%)] & $18(30)$ & $7(16.3)$ & $11(64.7)$ & \multirow{7}{*}{$<0.001^{* *}$} \\
\hline Development delay & $9(15)$ & $3(7.0)^{\ddagger}$ & $6(35.3)^{\ddagger}$ & \\
\hline Cerebral palsy & $3(5)$ & $2(4.7)$ & $1(5.9)$ & \\
\hline Congenital heart disease & $2(3.3)$ & $1(2.3)$ & $1(5.9)$ & \\
\hline Hyperactivity disorders & $3(5)$ & $1(2.3)$ & $2(11.8)$ & \\
\hline Bed-ridden & $1(1.6)$ & $0(0)$ & $1(5.9)$ & \\
\hline No comorbid condition & $42(70)$ & $36(83.7)^{\dagger}$ & $6(35.3)^{\dagger}$ & \\
\hline Body height less than $3^{\text {rd }}$ percentile[n (\%)] & $16(26.6)$ & $8(18.6)$ & $8(47.0)$ & $0.03^{*}$ \\
\hline Body weight less than $3^{\text {rd }}$ percentile[n (\%)] & $15(25)$ & $6(13.9)$ & $9(52.9)$ & $0.003^{*}$ \\
\hline \multicolumn{4}{|l|}{ POPC score $[\mathrm{n}(\%)]$} & \multirow{3}{*}{$<0.001^{* *}$} \\
\hline Favorable $(\leq 2)$ & $39(65)$ & $35(81.4)$ & $4(23.5)$ & \\
\hline Unfavorable ( $\geq 3$ ) & $21(35)$ & $8(18.6)$ & $13(76.5)$ & \\
\hline
\end{tabular}

Statistically significant $P$ values are bolded.

${ }^{*} P<0.05 ;{ }^{*} P<0.01$

$\ddagger$ The abused group had significantly more "development delay" patients as chronic comorbid condition

†The neglected group had less chronic comorbid condition significantly

POPC score: Pediatric overall performance category 
This retrospective study consisted of 60 patients (Table 1) suspected of being victims of child abuse or neglect at Kaohsiung Chang Gung Memorial Hospital and were admitted to the 20 beds-Pediatric Intensive Care Unit (PICU) from January 2011 to May 2017. These patients, who had failure to thrive, malnutrition, developmental delay, poor personal hygiene, failure/delay to seek medical care (such as immunization schedule, dermatitis, or vision correction), or intracranial hemorrhage or bone fracture caused by low-height falls, were evaluated by doctors, and referrals were made to social workers in cases of suspected abuse or neglect. After interviewing the case and his/her family, we classified cases into the abused group or neglected group based on general appearance, physical examination report, family history, and course of diseases. Then we reviewed patients' age, gender, general appearance, age when the event occurred, chronic comorbid conditions, immunization schedule, Glasgow Coma Scale (GCS), severity of disease (based on the Pediatric Risk of Mortality (PRISM) score) [9], hemoglobin level at admission, and length of PICU stay. The chronic comorbid conditions observed in this study included developmental delay, cerebral palsy, congenital heart disease, hyperactivity disorder, and bed-ridden status. We define patients that did not receive vaccines pursuant to the recommended schedule as interrupted vaccination, which means missing two shots in a series of the immunization schedule but does not include unintentional delays or deferring vaccines because of illness. Regarding skin lesion-like burns, bullae, and blue-green bruises (excluding traffic accident-related bruise), such lesions are considered red flags for child abuse.

\section{Intensive care management}

Furthermore, we compared patients who received an intubation or operation, had an initial presentation of intracranial hemorrhage, retinal hemorrhage, seizure, wound, bruise, or bone fracture on admission.

\section{Outcome}

Using information contained in the hospital record and telephone follow-up by social workers, we applied POPC score (Pediatric overall performance category) to access the oneyear functional outcome of each child approximately. Outcome categories were defined as $\mathrm{POPC}=1$ : good overall performance; POPC $=2$ : mild overall disability; $\mathrm{POPC}=3$ : moderate overall disability; $\mathrm{POPC}=4$ : severe overall disability; $\mathrm{POPC}=5$ : coma or vegetative state; POPC $=6$ : brain death [10]. The POPC $=1$ and 2 were regarded as having favorable outcome, while those who survived with POPC $=3,4,5$ or 6 were considered to have unfavorable outcome. We received approval for this study from the Institutional Review Board (IRB) of Chang Gung Memorial Hospital (IRB number: 201800528B0).

\section{Statistical analysis}

We analyzed data using the Kruskal-Wallis test and pairwise comparisons for continuous variables, and the chi-square test or Fisher's exact test for categorical variables. The data are presented by percentage, mean, and standard deviation (SD); Ap-value $<0.05$ is considered statistical significance. All statistical tests were carried out using SPSS 22.0 (SPSS, Inc., Chicago, Illinois).

\section{Results}

\section{Characteristics of children}

Table 2: Analysis of the risk factors for child abuse.

\begin{tabular}{|c|c|c|c|c|}
\hline & $\mathbf{N}(\%)$ & Neglected and accidents (n=43) & Abused (n=17) & p-value \\
\hline Vaccinated pursuant to the recommended schedule [n (\%)] & $51(85)$ & $42(97.7)$ & $9(52.9)$ & $<0.001^{* *}$ \\
\hline Initial intubation[n (\%)] & 24 & $19(44.2)$ & $5(29.4)$ & 0.293 \\
\hline Initial GCS $<8[\mathrm{n}(\%)]$ & 18 & $14 / 42(33.3)$ & $4 / 16(25.0)$ & 0.752 \\
\hline Initial Hemoglobin[median (IQR)] & $10.7(2.5)$ & $10.7(2.3)$ & $10.6(3.1)$ & 0.152 \\
\hline Seizure at diagnosis[n (\%)] & 21 & $8(18.6)$ & $13(76.5)$ & $<0.001^{* *}$ \\
\hline Intracranial hemorrhage[n (\%)] & 33 & $22 / 40(52.4)$ & $11 / 16(64.7)$ & 0.345 \\
\hline Craniotomy[n (\%)] & 22 & $14(32.6)$ & $8(47.1)$ & 0.294 \\
\hline Retinal hemorrhages[n (\%)] & 16 & $8(18.6)$ & $8(47.1)$ & $0.049^{*}$ \\
\hline Skin lesions[n (\%)] & 19 & $10 / 42(23.8)$ & $9(52.9)$ & $0.030^{*}$ \\
\hline Fractures[n (\%)] & 15 & $11 / 42(26.2)$ & $4(23.5)$ & 1.000 \\
\hline Length of stay in ICU[days; median (IQR)] & $7(10.3)$ & $5(8.3)$ & $17.5(28.5)$ & $0.001^{* *}$ \\
\hline
\end{tabular}

\#GCS: Glasgo Coma Scale

Statistically significant $P$ values are bolded

${ }^{*} \mathrm{P}<0.05 ;{ }^{* *} \mathrm{P}<0.01$ 
Table 3: Details in 17 abused patients underwent inflicted injury.

\begin{tabular}{|c|c|c|c|c|c|c|c|}
\hline Case no. & Sex & Age & $\begin{array}{c}\mathrm{BW}(\mathrm{Kg}) \\
\text { (percentile) }\end{array}$ & $\begin{array}{c}\mathrm{BH}(\mathrm{cm}) \\
\text { (percentile) }\end{array}$ & Comorbid $^{\sharp}$ & $\begin{array}{l}\text { vaccination on } \\
\text { schedule }\end{array}$ & $\begin{array}{c}\text { Physical abuse } \\
\text { events }^{\natural}\end{array}$ \\
\hline 1 & $\mathrm{M}$ & $8 \mathrm{mo}$ & $6.8(<3)$ & $61.5(<3)$ & $\mathrm{V}$ & Y & AHT, bone fracture \\
\hline 2 & M & $8 \mathrm{mo}$ & $6.9(<3)$ & $65(<3)$ & I & Y & AHT \\
\hline 3 & M & $2 \mathrm{mo}$ & $6.4(50-85)$ & $60(15-50)$ & no & Y & AHT \\
\hline 4 & M & $6 \mathrm{y} 2 \mathrm{mo}$ & $12.6(<3)$ & $92(<3)$ & IV & $\mathrm{N}$ & Liver laceration \\
\hline 5 & M & $4 \mathrm{mo}$ & $5.8(3-15)$ & $62(<3)$ & no & $\mathrm{Y}$ & AHT \\
\hline 6 & $\mathrm{M}$ & $1 \mathrm{y} 10 \mathrm{mo}$ & $12(50-85)$ & $83(15-50)$ & I & $\mathrm{N}$ & $\mathrm{AHT}$ \\
\hline 7 & M & $6 \mathrm{mo}$ & $7(<3)$ & $65(3-15)$ & No & $\mathrm{Y}$ & AHT \\
\hline 8 & M & $8 \mathrm{mo}$ & $8(3-15)$ & $75(>97)$ & I & $\mathrm{Y}$ & Immersion \\
\hline 9 & $\mathrm{~F}$ & $2 \mathrm{mo}$ & $5.6(15-50)$ & $62(50-85)$ & No & $\mathrm{Y}$ & AHT \\
\hline 10 & $\mathrm{~F}$ & $2 \mathrm{y} 9 \mathrm{mo}$ & $9.5(<3)$ & $87(3-15)$ & No & $\mathrm{Y}$ & AHT \\
\hline 11 & M & $1 y$ & $7(<3)$ & $50(<3)$ & III & $\mathrm{N}$ & AHT \\
\hline 12 & M & $8 \mathrm{mo}$ & $6(<3)$ & $65(<3)$ & No & $Y$ & AHT \\
\hline 13 & $\mathrm{~F}$ & $6 \mathrm{y} 6 \mathrm{mo}$ & $20(50-85)$ & $115(50-85)$ & No & Y & $\begin{array}{l}\text { Skull bone fracture, } \\
\text { multiple abrasion }\end{array}$ \\
\hline 14 & M & $7 \mathrm{mo}$ & $7.5(50-85)$ & $75(15-50)$ & I & Y & AHT \\
\hline 15 & M & $6 \mathrm{mo}$ & $6.3(<3)$ & $69(50-85)$ & I & $\mathrm{N}$ & AHT \\
\hline 16 & M & $1 \mathrm{y} 8 \mathrm{mo}$ & $7.6(<3)$ & $73(<3)$ & I & $\mathrm{N}$ & $\begin{array}{l}\text { Multiple ecchymosis } \\
\text { and AHT }\end{array}$ \\
\hline 17 & M & $9 \mathrm{mo}$ & $9(15-50)$ & $68((<3)$ & No & $\mathrm{Y}$ & AHT \\
\hline
\end{tabular}

Chronic comorbid condition:

I-developmental delay; II-cerebral palsy; III-congenital heart disease; IV-hyperactivity disorder; V bed-ridden status AHT: Abusive head trauma

Among the 60 patients recruited for this study, 40 were boys and 20 were girls. The median age when the abused or neglected event occurred was 9 months old [median (IQR): 19]. There were 17 patients were recognized as abused group (shown in Table 3) while other 43 patients were belonged to neglected group according to medical staff's mandatory reports. The table 1 showed demographic data including 18 patients had chronic comorbid conditions like congenital heart disease, growth retardation, and cerebral palsy ,16 (26.6\%) patients were under height (less than $3^{\text {rd }}$ percentile) and 15 (15\%) patients were underweight(less than $3^{\text {rd }}$ percentile); Table 2 shows that 51 patients were vaccinated on schedule, 24 patients had intubation,18 of which had a Glasgow Coma Scale score less than 8 . The initial mean hemoglobin level was $10.7 \pm 2.5 \mathrm{~g} / \mathrm{dL}$, and 21 patients had new onset seizure while hospitalized in the PICU; 33 patients had intracranial hemorrhage, and 22 patients underwent cranial surgery; 16 patients had retinal hemorrhage; 19 patients had visual skin lesions; 15 patients had bone fracture. The mean length of patients' hospitalization in PICU is $7 \pm 10.3$ days.

\section{Risk factors}

We divided the patients into the abused group and the neglected group and compared the differences between the two groups. The abused group demonstrated a statically significant higher incidence of chronic comorbid conditions (especially in development delay), failure to thrive (body weight and body height less than $3^{\text {rd }}$ percentile) and interrupted vaccination than neglected group $(\mathrm{P}<0.001$ for both; Table 1$)$. The abused group also had more patients diagnosed with seizure upon admission than the neglected group $(\mathrm{P}<0.001$; Table 2$)$. Regarding length of hospital stay, the mean stay lengths are 17.5 days and 5 days in the abused group and the neglected group, respectively $(\mathrm{P}<0.001$; Table 2).

\section{Outcome}

All of the children 51(85\%) had follow-up either through medical records or telephone follow-up except for 9(15\%) death. The one-year outcome POPC score were applied. Using POPC score, $39(65 \%)$ patients were belonged to favorable outcome while $21(35 \%)$ patients underwent unfavorable outcome. No patients survived in a coma or persistent vegetative state (POPC=5). The post-injury functional outcome in the two groups were shown in Figure 1. We compared the favorable or unfavorable functional outcome in our abused or neglected group. We found the neglected group had significantly favorable outcome ( $<<0.001$; Table 1$)$. 


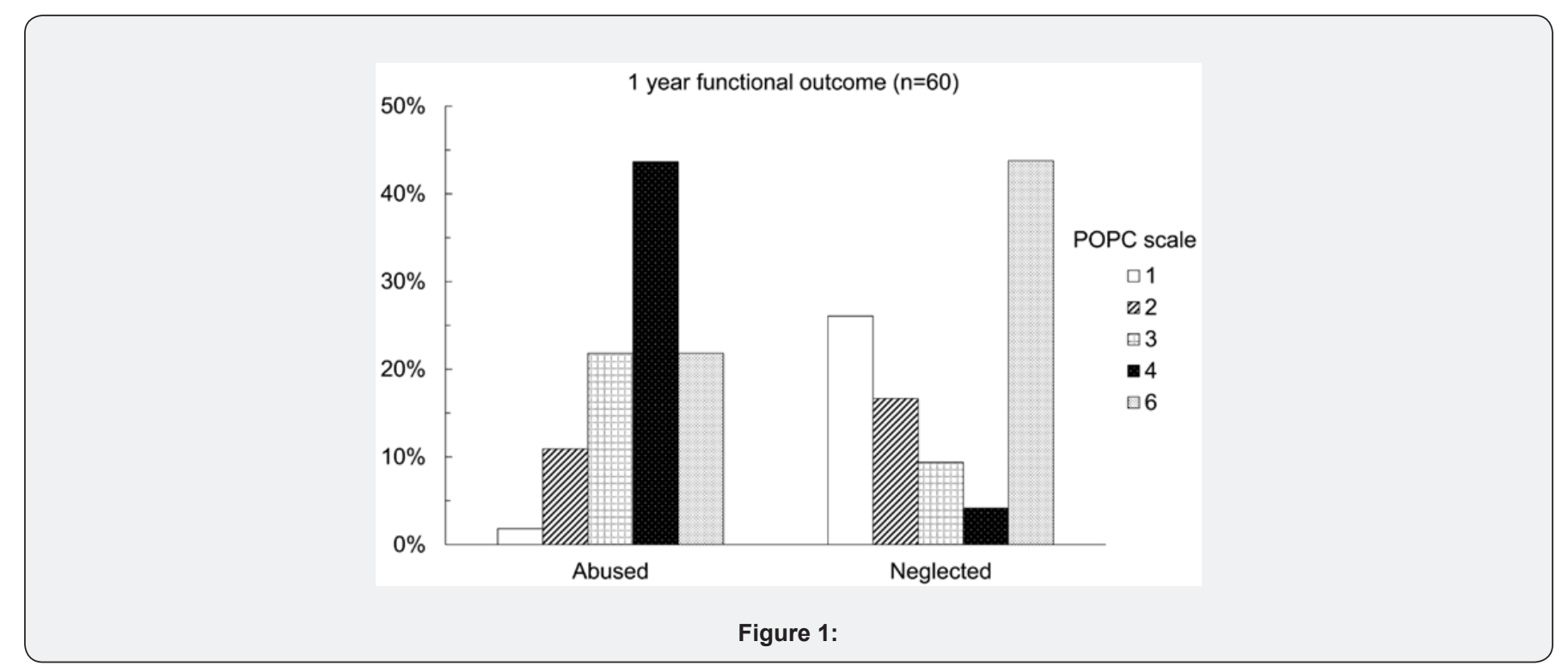

\section{Discussion}

The initial presentation of child maltreatment may be subtle or may be catastrophic. In our study, we found that the abused group has more patients diagnosed with skin lesions, seizures on admission, and retinal hemorrhage than the neglected group $(\mathrm{P}=0.03, \mathrm{P}<0.001$, and $\mathrm{P}=0.049$, respectively, as shown in Table 2). In a previous study, Maguire et al. analyzed the clinical features of abusive head trauma (AHT) and found that combining intracranial injury with retinal hemorrhage raised the probability of AHT from $4 \%$ (intracranial injury only) to 58\%; however, head and/or neck bruising had a less significant relation with AHT. Intracranial injury and the presentation of head and/or neck bruising only elevated the probability of AHT from 4\% (intracranial injury only) to $15 \%$ [11]. Our study revealed that skin lesions and retinal hemorrhage had significant increased relationship with child abuse, but intracranial hemorrhage did not significantly differ between the two groups. Which correlate the previous studies. O'Neill et al. assessed seizure with continuous electroencephalography (EEG) in patients with traumatic brain injuries and observed that young age and an abusive head trauma mechanism were both strong predictors of seizure (odds ratios [ORs] 8.7 and 6.0, respectively; $\mathrm{p}<0.0001$ for both) [12]. Child maltreatment has adverse effects on the affected children's physical condition, as well as the community's health care finance. Our study revealed longer PICU stays for abused children (17.5 days vs. 5 days for abused vs. neglected and accident children, respectively, $\mathrm{p}=0.001$ ). En-Pei Lee et al. retrospectively reviewed cases of child maltreatment admitted to Chang Gung Memorial Hospital at Linkou from 2001 to 2015 and observed that the abusive trauma group had longer stays in the ICU than the neglectful trauma group (18.2 \pm 23.9 days vs $7.2 \pm 6.9$ days respectively, $\mathrm{p}<0.01$ ), and often a worse prognosis [13]. Children who were diagnosed as abused or neglected were more likely to die during hospitalization, have longer hospital stays, and have greater medical expenses [14-18]. These were compatible with our outcome analysis which neglected patients tended to have significantly better outcome and shorter ICU stay. Furthermore, some discharges were delayed despite medical clearance due to a lack of safe deposition [17]. Referral to multidisciplinary child protective service organizations significantly reduces the avoidable days of hospitalization and health care waste [19].

The abused children had a higher probability of chronic comorbid conditions, especially in development delay and interrupted vaccination compared with the neglected children in our study. Delays in seeking medical care raises concerns about potential abuse, [20]. while failure to thrive can be a manifestation of child maltreatment [21]. In our study, patients who were failure to thrive also had significant tendency of child abuse. Children with disabilities or chronic illnesses are also at the risk of being abused [22-24]. Demanding special health care may test a caregiver's patience, and children with disabilities are 3.4 times more likely to be maltreated than children without disabilities [25]. Furthermore, children with disabilities have greater difficulty reporting abusive events and fighting against caregivers. A longitudinal study of low-income children revealed that children with maltreatment reports also had a $74-100 \%$ higher risk of hospital treatment for asthma, cardio-respiratory, and non-sexually transmitted infectious disease [26]. While the negative health impact of maltreatment occurs prior to adulthood, it also has life-long consequences. A systemic review and metaanalysis revealed an association between adults' mental disorder, substance abuse and childhood maltreatment, and some evidence also suggests a significant association between child physical abuse and arthritis, ulcers, and headache/migraine in adulthood [27]. All forms of maltreatment contribute to risk factors of chronic disease and area burden on health economics. Awareness 
and early intervention and household visits to children with the risk of being abused can protect children from victimization. Our study has some limitations. First, as a retrospective study, it has recall bias and reverse causality. We were unable to completely obtain some cases' characteristics and chronic comorbid conditions. The caregivers that may lose patience in dealing with their children's chronic diseases may have a higher tendency of child maltreatment, while the caregivers' abuse or neglect of children may worsen children's diseases. Second, the amount of child maltreatment in our study could be underestimated. Most referrals rely on communities and medical providers, but the Taiwanese culture discourages third-party intervention, and some of the cases are lost during the follow-up period. More studies are needed in the future to ensure that victims are recognized early.

\section{Conclusion}

In our study, we found that abused children tend to have a higher incidence of chronic comorbid conditions, seizure, interrupted vaccination, longer length of PICU stay and poor functional outcome. This situation cannot be overemphasized as it affects not only public health but also social welfare and financial burdens. More and more organizations are advocating "early recognition, early referral" and have launched lectures to educate medical professionals. By better understanding the importance of early intervention against abuse, we can take action to save these children and prevent tragedies.

\section{References}

1. Caffey J (1946) Multiple fractures in the long bones of infants suffering from chronic subdural hematoma. Am J Roentgenol Radium Ther 56(2): $163-173$

2. Kempe CH, Silverman FN, Steele BF, Droegemueller W, Silver HK (1962) The battered-child syndrome. JAMA 181:17-24.

3. Myers JEB (2008) A Short History of Child Protection in America. Family Law Quarterly 42(3): 449-464.

4. Etienne G, Krug LLD, James A Mercy, Anthony B Zwi, Rafael Lozano (2002) Child abuse and neglect by parents and other caregivers. World report on violence and health 57-81.

5. Kurt Heisler (2017) Child Maltreatment 2015. Department of Health \& Human Services, Administration for Children and Families, Administration on Children, Youth and Families, Children's Bureau 18.

6. Gilbert R, Widom CS, Browne K, Fergusson D, Webb E, et al. (2019) Burden and consequences of child maltreatment in high-income countries. Lancet 373(9657): 68-81.

7. Lansford JE, Dodge KA, Pettit GS, Bates JE, Crozier J, et al. (2002) A 12year prospective study of the long-term effects of early child physical maltreatment on psychological, behavioral, and academic problems in adolescence. Arch Pediatr Adolesc Med. 156(8): 824-830.

8. Sebre S, Sprugevica I, Novotni A, Bonevski D, Pakalnisklene V, et al (2004) Cross-cultural comparisons of child-reported emotional and physical abuse: rates, risk factors and psychosocial symptoms. Child Abuse Negl 28(1): 113-127.

9. Pollack MM, Ruttimann UE, Getson PR (1986) Pediatric risk of mortality (PRISM) score. Crit Care Med 16(11): 1110-1116.
10. Fiser DH, Long N, Roberson PK, Hefley G, Zolten K, et al. (2000) Relationship of pediatric overall performance category and pediatric cerebral performance category scores at pediatric intensive care unit discharge with outcome measures collected at hospital discharge and 1- and 6-month follow-up assessments. Crit Care Med 28(7): 26162620.

11. Maguire SA, Kemp AM, Lumb RC, Farewell DM (2011) Estimating the probability of abusive head trauma: a pooled analysis. Pediatrics. 128(3): 550-564.

12. O'Neill BR, Handler MH, Tong S, Chapman KE (2015) Incidence of seizures on continuous EEG monitoring following traumatic brain injury in children. J Neurosurg Pediatr 16(2): 167-176.

13. Lee EP, Hsia SH, Huang JL, Lin JJ, Chan OW, et al. (2017) Epidemiology and clinical analysis of critical patients with child maltreatment admitted to the intensive care units. Medicine (Baltimore) 96(23): 7107.

14. Rovi S, Chen P-H, Johnson MS (2004) The Economic Burden of Hospitalizations Associated with Child Abuse and Neglect. American Journal of Public Health 94(4): 586-590.

15. Russo CA, Hambrick MM, Owens PL (2008) Hospital Stays Related to Child Maltreatment, 2005: Statistical Brief \#49 Healthcare Cost and Utilization Project (HCUP) Statistical Briefs.

16. Lane WG, Lotwin I, Dubowitz H, Langenberg P, Dischinger P (2011) Outcomes for Children Hospitalized With Abusive Versus Noninflicted Abdominal Trauma. Pediatrics 127(6): 1400-1405.

17. Lee M, Bachim A, Smith C, Camp EA, Donaruma-Kwoh M, et al. (2017) Hospital Costs and Charges of Discharge Delays in Children Hospitalized for Abuse and Neglect. Hosp Pediatr 7(10): 572-578.

18. Chang YC, Huang JL, Hsia SH, Lin KL, Lee EP, et al. (2016) Child protection medical service demonstration centers in approaching child abuse and neglect in Taiwan. Medicine (Baltimore) 95(44): 5218.

19. Davenport CM, Stricklin C, Oviedo A, Sumner B, Rodriguez S, et al. (2017) Decreasing the Length of Stay for Hospitalized Children with a Referral to Child Protective Services. Pediatrics 140(1): 43.

20. Dubowitz H, Bennett S (2007) Physical abuse and neglect of children. The Lancet 369(9576): 1891-1899.

21. Block RW, Krebs NF (2005) Failure to Thrive as a Manifestation of Child Neglect. Pediatrics 116(5): 1234-1237.

22. Flaherty EG, Stirling J (2010) Clinical Report-The Pediatrician's Role in Child Maltreatment Prevention. Pediatrics 126(4): 833-841.

23. Hibbard RA, Desch LW (2007) Maltreatment of Children with Disabilities. Pediatrics. 119(5): 1018-1025.

24. Jaudes PK, Diamond LJ (1986) Neglect of chronically ill children. Am J Dis Child 140(7): 655-658.

25. Sullivan PM, Knutson JF (2000) Maltreatment and disabilities: a population-based epidemiological study. Child Abuse Negl 24(10): 1257-1273.

26. Lanier P, Jonson-Reid M, Stahlschmidt MJ, Drake B, Constantino J (2010) Child maltreatment and pediatric health outcomes: a longitudinal study of low-income children. J Pediatr Psychol 35(5): 511-522.

27. Norman RE, Byambaa M, De R, Butchart A, Scott J, et al. (2012) The long-term health consequences of child physical abuse, emotional abuse, and neglect: a systematic review and meta-analysis. PLoS Med. 9(11): 1001349. 
This work is licensed under Creative

Commons Attribution 4.0 Licens

DOI: 10.19080/AJPN.2020.08.555803
Your next submission with Juniper Publishers will reach you the below assets

- Quality Editorial service

- Swift Peer Review

- Reprints availability

- E-prints Service

- Manuscript Podcast for convenient understanding

- Global attainment for your research

- Manuscript accessibility in different formats ( Pdf, E-pub, Full Text, Audio)

- Unceasing customer service

Track the below URL for one-step submission https://juniperpublishers.com/online-submission.php 